\title{
Novel Phospho-Tau Monoclonal Antibody Generated Using a Liposomal Vaccine, with Enhanced Recognition of a Conformational Tauopathy Epitope
}

\author{
Clara Theunis $^{\mathrm{a}, 1}$, Oskar Adolfsson ${ }^{\mathrm{b}, 1}$, Natalia Crespo-Biel ${ }^{\mathrm{a}}$, Kasia Piorkowska ${ }^{\mathrm{b}}$, Maria Pihlgren $^{\mathrm{b}}$, \\ David T. Hickman ${ }^{\mathrm{b}}$, Valérie Gafner ${ }^{\mathrm{b}}$, Peter Borghgraef ${ }^{\mathrm{a}}$, Herman Devijver ${ }^{\mathrm{a}}$, Andrea Pfeifer ${ }^{\mathrm{b}}$, \\ Fred Van Leuven ${ }^{\mathrm{a}}$ and Andreas Muhs ${ }^{\mathrm{b}, *}$ \\ ${ }^{a}$ Experimental Genetics Group - LEGTEGG, Department of Human Genetics, KULeuven, Leuven, Belgium \\ ${ }^{\mathrm{b}}$ AC Immune SA, EPFL Innovation Park, Building B, Lausanne, Switzerland
}

Handling Associate Editor: Khalid Iqbal

Accepted 2 November 2016

\begin{abstract}
The microtubule-associated protein Tau is an intrinsically unfolded, very soluble neuronal protein. Under still unknown circumstances, Tau protein forms soluble oligomers and insoluble aggregates that are closely linked to the cause and progression of various brain pathologies, including Alzheimer's disease. Previously we reported the development of liposome-based vaccines and their efficacy and safety in preclinical mouse models for tauopathy. Here we report the use of a liposomal vaccine for the generation of a monoclonal antibody with particular characteristics that makes it a valuable tool for fundamental studies as well as a candidate antibody for diagnostic and therapeutic applications. The specificity and affinity of antibody ACI-5400 were characterized by a panel of methods: (i) measuring the selectivity for a specific phospho-Tau epitope known to be associated with tauopathy, (ii) performing a combination of peptide and protein binding assays, (iii) staining of brain sections from mouse preclinical tauopathy models and from human subjects representing six different tauopathies, and (iv) evaluating the selective binding to pathological epitopes on extracts from tauopathy brains in non-denaturing sandwich assays. We conclude that the ACI-5400 antibody binds to protein Tau phosphorylated at S396 and favors a conformation that is typically present in the brain of tauopathy patients, including Alzheimer's disease.
\end{abstract}

Keywords: Antibody binding sites, Alzheimer's disease, monoclonal antibody, protein conformation, tauopathies

\section{INTRODUCTION}

Worldwide, more than 46 million people are diagnosed with dementia, a number that is expected to triple by 2050 [1]. This increase in Alzheimer's disease $(\mathrm{AD})$ prevalence, and in dementia in general is directly associated with aging, and brings

\footnotetext{
${ }^{1}$ These authors contributed equally to this work.

${ }^{*}$ Correspondence to: Andreas Muhs, AC Immune SA, EPFL Innovation Park, Building B, CH-1015 Lausanne, Switzerland. Tel.: +41 2134591 24; Fax: +41 2134591 20; E-mail: andreas.muhs@acimmune.com.
}

about severe personal, social, and economic burden. The situation underlines the urgency needed in our efforts to develop effective treatments to cure, curb, or eventually prevent devastating neurological diseases. Various brain enzymes, receptors, and structural proteins were proposed as pharmacological targets and several therapeutic agents are in different stages of development and testing. More recently, studies have raised hope that targeting Tau with either aggregation inhibitors or by immunotherapy may bring about clinical benefits in $\mathrm{AD}$ and tauopathy patients (for recent reviews see: [2-4]). 
Protein Tau is the major pathological player in specified primary tauopathies, where mutations in the MAPT gene encoding Tau are the cause for the development of Tau pathology and the related memory decline [5]. For AD, the amyloid cascade hypothesis provides a compelling basis for the pathological role of amyloid- $\beta$ [6]. Although AD is classically designated as a secondary tauopathy, Tau is the most prominent co-morbid factor with measures of Tau pathology correlating better with cognitive decline compared to amyloid [7-9]. Interest in Tau as a target has increased over the last decade and ongoing studies investigate a wide range of fundamental structural and functional features. The CSF levels of both total and phospho-Tau (pTau) are currently used as diagnostic biomarkers, while more recently Tau protein is also being proposed as an important therapeutic target as has been suggested by a number of published animal studies [10-21].

Active immunization targeting pathological amyloid peptides was the first study in transgenic mice to show a benefit in using immunotherapy to counteract pathological protein conformers in the central nervous system (CNS) [22]. Since then, studies using active immunotherapy against the Tau protein have also shown efficacy in tauopathy models, suggesting Tau as another important CNS immuno target [10-12]. Additional studies have now shown passive anti-Tau vaccination as an alternative modality to target Tau in CNS, with several proof-of-concept passive immunizations directed at various Tau epitopes [13-21].

Although increased in pathology, phosphorylation of protein Tau is a normal physiological modification, in contrast with conformational changes that are commonly annotated as pathological. The exact temporal order of specific phosphorylation and conformational changes of protein Tau is not known, nor their exact relation to the formation of oligomers and aggregates, typical for all tauopathies. Consequently, monoclonal antibodies (Mab) with a combined or complex specificity for phosphorylated conformers of presumed pathological Tau species are highly wanted for fundamental studies and eventually for more specific and efficacious diagnosis and therapy. Along with the need for disease modifying therapy comes the need for biomarkers to diagnose $\mathrm{AD}$ as early as possible, unambiguously and distinct from other CNS disorders. Protein Tau, both total and phospho-Tau, remains one of the most informative molecular biomarkers in CSF because of the close correlation tauopathy has with cognitive deterioration in $\mathrm{AD}$ patients [23-25].

The growing interest to target Tau by immunotherapy, and its use as biomarker, complements the primary application of antibodies in fundamental research to define specific biochemical and physical Tau-isoforms. The physiological function of protein Tau as a microtubule-associated-protein (MAP) and especially the implicit contribution of phosphorylation and other post-translational modifications are still not fully understood. Similarly, the contribution of post-translational modifications to Tau pathology were shown to be important but the roles these modifications play in the development of disease in different tauopathies needs further study, particularly in terms of timing and brain-regional specificity. Probes that reveal as yet unknown structural and functional characteristics of protein Tau are therefore valuable as tools to support or exclude the many different hypotheses in this field.

These arguments inspired us to generate novel antibodies with distinct properties by use of our liposome-based vaccines that proved both safe and efficacious [10, 26-29]. We incorporated into liposomes synthetic phosphorylated peptides that mimic important phospho-epitopes of protein Tau [10]. The phospho-peptide antigen incorporated onto the liposomal surface was formulated to target a pathological phosphorylation site on Tau [30], and to adopt a $\beta$-sheet secondary conformation, similar to that of aggregated Tau. Furthermore, the staining of tauopathy in brain sections confirmed that the polyclonal antibodies induced in response to this vaccine covered potentially interesting and valuable epitopes. From wild-type and transgenic mice vaccinated with these Tau-based liposomes, we derived Mabs and selected for high binding affinity and specificity by optimized biochemical and immunohistochemical assays. Here we present data on one Mab with high affinity for protein Tau phosphorylated at S396. The epitope is present in a pathological conformation that is encountered in neurofibrillary tangles and neuropil threads in the brain of preclinical mouse models and of tauopathy patients, including AD.

\section{MATERIALS AND METHODS}

\section{Generation of monoclonal antibodies}

The phospho-Tau (pTau) specific IgG2bк antibody ACI-5400 was generated in mice vaccinated 
with a tetra-palmitoylated, bi-phosphorylated peptide Tau393-408[pS396/pS404] coupled to an adjuvant-containing liposome [10]. Hybridomas and monoclonal antibodies were produced by classical methods, and the hybridoma subclones were adapted to serum-free culture conditions in spinner systems. Mabs were purified by protein-A/G affinity chromatography, followed by sterile filtration and quantification. Quality control was done by capillary electrophoresis and analytical size-exclusion chromatography. Antibodies were stored in small aliquots at $-80^{\circ} \mathrm{C}$. All animal experiments were in compliance with protocols approved by local animal care and use committees.

\section{ELISA to measure antibody selectivity for Tau and pTau}

To define the selectivity of the generated antibodies for phosphorylated Tau peptides and protein, we assessed their binding by ELISA on the phosphorylated Tau peptide (pTau peptide) used in the vaccine, on the non-phosphorylated version of this Tau peptide (Tau peptide), as well as on full-length recombinant human protein Tau, either phosphorylated [31] or not phosphorylated (Tau protein; SignalChem, Canada).

MaxiSorp 96-well plates (Nunc, Roskilde, Denmark) were coated with peptides at high density $(10 \mu \mathrm{g} / \mathrm{ml})$ or full-length proteins at $(1 \mu \mathrm{g} / \mathrm{ml})$ by overnight incubation at $4^{\circ} \mathrm{C}$ [31]. To test for eventual cross-reactivity to Tau and pTau sequences that were not used in the vaccine, the plates were coated with the following peptides: Tau5-20 (phosphorylated or not on Y18), Tau401-418 (phosphorylated or not on S404 and S409), Tau206-221 (phosphorylated or not on T212 and S214), and Tau196-211 (phosphorylated or not on S202 and T205) all at $10 \mu \mathrm{g} / \mathrm{ml}$. As an additional negative control, plates were coated with bovine serum albumin (BSA; Sigma-Aldrich, Lyon, France). After washing (0.05\% Tween-20 in PBS), non-specific binding sites were blocked for $1 \mathrm{~h}$ at $37^{\circ} \mathrm{C}$ with $1 \%$ BSA in the same buffer. Subsequently, serial dilutions of the antibody were incubated for $2 \mathrm{~h}$ at $37^{\circ} \mathrm{C}$. Plates were then again extensively washed and alkaline phosphatase conjugated anti-mouse IgG secondary antibody (Jackson ImmunoResearch, Newmarket, UK) was added at $1 / 6^{\prime} 000$ dilution in blocking buffer for $2 \mathrm{~h}$ at $37^{\circ} \mathrm{C}$. After another wash, plates were incubated with para-nitro-phenyl-phosphate disodium hexahydrate (pNPP) phosphatase substrate solution at room temperature (RT) in the dark. The reaction was stopped and the optical density (O.D.) was recorded at $405 \mathrm{~nm}$ using an ELISA plate reader. Results are expressed as O.D.

\section{Surface Plasmon Resonance binding assay}

Surface Plasmon Resonance (SPR) binding assays were done in PBS buffer, with the sensor chip coated with streptavidin covalently linked to carboxymethyl dextran (GE Healthcare, Locarno, Switzerland). The SPR assays were performed using a Biacore $\mathrm{X}$ instrument (GE Healthcare). After conditioning (PBS at $30 \mu \mathrm{l} / \mathrm{min}$ ), a stable baseline was established by injecting pulses of $1 \mu \mathrm{l}$ $16 \mathrm{mM} \mathrm{NaOH}$ in both flow cells. The synthetic biotinylated Tau393-408 (pS396/pS404) peptide (N-biotinyl-6-aminohexylamide linker-G-VYKS $\left[\mathrm{PO}_{3} \mathrm{H}_{2}\right] \mathrm{PVVSGDTS}\left[\mathrm{PO}_{3} \mathrm{H}_{2}\right] \mathrm{PRHL}-\mathrm{NH}_{2}$; Protein and Peptide Chemistry Facility, University of Lausanne, Switzerland) was dissolved at $1 \mu \mathrm{M}$ in PBS, and injected to cover the chip of flow-cell 2 $(5 \mu \mathrm{l} / \mathrm{min}$, total $35 \mu \mathrm{l}$, final immobilization level of $130 \mathrm{RU})$. Serial dilutions of antibodies in PBS were injected ( $50 \mu \mathrm{l} / \mathrm{min}, 120 \mathrm{~s})$. Flow cell 1 was not derivatized and its responses subtracted as blanks from readings in flow-cell 2. After each injection, chip surfaces were washed with PBS (100s) and regenerated by injecting $1 \mu \mathrm{l} 10 \mathrm{mM}$ Glycine- $\mathrm{HCl}$ $(\mathrm{pH}$ 1.7). Kinetic analysis was performed using algorithms for numerical integration and global analysis (BIAevaluation 3.0). All data were fit to a $1: 1$ homogeneous Langmuir model [32].

\section{Immunohistochemistry for tauopathy (TAUPIR)}

Antibodies were analyzed for their specificity to bind aggregated Tau as neurofibrillary tangles and neuropil threads in free-floating vibratome sections $(40 \mu \mathrm{m})$ from the brain of old bigenic biGT mice with proven dramatic tauopathy [10, 33]. Mab AT100 (Innogenetics, Ghent, Belgium) was used as the standard pathological marker, specifically reacting with pT212/pS214-Tau. The negative controls were free-floating vibratome sections from old Tau knock-out (TKO) mice, lacking protein Tau [33]. Antibodies were further evaluated for their specificity for Tau pathology in human brain sections from subjects diagnosed with different tauopathies, including sporadic $\mathrm{AD}$, familial $\mathrm{AD}$, argyrophilic grain disease, frontotemporal dementia with parkinsonism linked to chromosome 17 carrying the MAPT P301L mutation, corticobasal degener- 
ation, and progressive supranuclear palsy. Paraffin sections were generously provided by Prof. Hans A. Kretzschmar (Münich, Germany). The sections were de-paraffinized by 2 passages in xylol $(5 \mathrm{~min})$, 2 times in $100 \%$ ethanol ( $1 \mathrm{~min}$ ), followed by $90 \%$, $70 \%$, and $50 \%$ ethanol, distilled water and PBS (each $1 \mathrm{~min}$ ). Antigen retrieval was done by boiling the sections for $10 \mathrm{~min}$ in $0.01 \mathrm{M}$ citric acid (pH 6.0) and after cooling, incubation for $15 \mathrm{~min}$ at RT in $1.5 \% \mathrm{H}_{2} \mathrm{O}_{2}$ in PBS:methanol $(1: 1)$ to block endogenous peroxidase activity. After washing 3 times in PBST (PBS/0.05\% Tween-20), sections were incubated for $30 \mathrm{~min}$ at RT in $10 \%$ fetal calf serum in PBST. Incubation was overnight at $4^{\circ} \mathrm{C}$ with either the novel antibodies, or with AT8 (pS202/pT205-Tau) or AT100 (pT212/pS214-Tau) as positive controls (Innogenetics, Ghent, Belgium) [34-36]. Next, sections were washed in PBST before incubation ( $1 \mathrm{~h}, \mathrm{RT})$ with horseradish peroxidase (HRP)-conjugated goat anti-mouse secondary antibody (DAKO, Glostrup, Denmark), diluted 1/500 in blocking buffer. After the sections were washed 3 times in PBS and incubated in $50 \mathrm{mM}$ Tris$\mathrm{HCl} \mathrm{(pH} \mathrm{7.6)} \mathrm{for} 5 \mathrm{~min}$, signal was generated by incubation for $3 \mathrm{~min}$ with diaminobenzidine in $50 \mathrm{mM}$ Tris- $\mathrm{HCl}$ and $0.3 \% \mathrm{H}_{2} \mathrm{O}_{2}$. The reaction was stopped by washing 3 times in PBS and the sections counterstained with Mayer's hematoxylin before dehydration with increasing ethanol and xylol. Finally, sections were mounted with DePex (BDH Chemicals, Poole, England) under glass cover-slips. Stained sections were examined microscopically and digital images collected and analyzed using dedicated software (IM500, Leica, Germany). Double staining of Mabs with different phospho-Tau antibodies was done on free floating vibratome sections $(40 \mu \mathrm{M})$ from biGT mice. Sections were washed $3 \times 5 \mathrm{~min}$ in PBST after which they were blocked to prevent non-specific binding with $10 \%$ fetal calf serum in PBST for $30 \mathrm{~min}$ at RT. Sections were incubated overnight at $4^{\circ} \mathrm{C}$ with Mabs in combination with either AT100 (Innogenetics, Ghent, Belgium), MC1 (generously provided by Peter Davies, New York, NY, USA), or with polyclonal antibody pS396 (Invitrogen, Brussels, Belgium). Sections were washed in PBST and incubated for $60 \mathrm{~min}$ with specific secondary antibodies coupled to Alexa-594 or Alexa488. The sections were washed and incubated for 10 min in 4\% paraformaldehyde in PBS. Lipofuscin autofluorescence was eliminated (Autofluorescence Eliminator Reagents; Merck Millipore, Overijse, Belgium) before sections were mounted in Mowiol and analyzed by confocal microscopy. For all antibodies, optimal dilutions were determined for staining on free-floating or on paraffin sections, as indicated in the results.

\section{Homogenization and fractionation of mouse brains}

Total homogenate was prepared from the forebrain and brainstem of mice with the following genotypes: wild-type FVB, Tau deficient mice (TKO; Jackson Labs, Bar Harbor, Maine, USA), Tau P301L mice (denoted as TPLH), GSK3 $\beta$ S9A $\times$ Tau P301L bigenic mice (denoted as biGT; [37]), and hTau4R $\times$ TKO mice (denoted as TT4.TKO; [10, 33, $38,39])$. Frozen brain tissue was homogenized with a motor-driven glass-pestle homogenizer $(700 \mathrm{rpm}$, in ice-bath) in 6 volumes of cold homogenization buffer: $25 \mathrm{mM}$ Tris. $\mathrm{HCl}$ (pH 7.6), $150 \mathrm{mM} \mathrm{NaCl}, 1 \mathrm{mM}$ EDTA, $1 \mathrm{mM}$ EGTA, $30 \mathrm{mM} \mathrm{NaF}, 0.2 \mathrm{mM} \mathrm{Na}_{3} \mathrm{VO}_{4}$, $1 \mathrm{nM}$ okadaic acid, $1 \mathrm{mM}$ phenylmethylsulfonyl fluoride (PMSF), $5 \mathrm{mM} \mathrm{Na} 4 \mathrm{P}_{2} \mathrm{O}_{7}$, and complete protease inhibitor cocktail (1 tablet CPIC per $12 \mathrm{ml}$; Roche, Belgium). An aliquot (20\% of total volume) was stored at $-20^{\circ} \mathrm{C}$. The remaining aliquot $(80 \%$ of volume) was centrifuged $\left(30 \mathrm{~min}, 1 / 150^{\prime} 000 \times \mathrm{g}, 4^{\circ} \mathrm{C}\right.$ ) and the supernatant (denoted as $\mathrm{S} 1$ soluble fraction) stored at $-80^{\circ} \mathrm{C}$. The pellet was resuspended in cold TBS (10 mM Tris. $\mathrm{HCl}, \mathrm{pH} 7.4,0.8 \mathrm{M} \mathrm{NaCl})$ with $10 \%$ sucrose, $1 \mathrm{mM}$ EGTA, $1 \mathrm{mM}$ PMSF, and centrifuged briefly. The supernatant was adjusted to $1 \%(\mathrm{w} / \mathrm{v})$ sarkosyl and after incubation for $1 \mathrm{~h}$ at RT centrifuged ( $30 \mathrm{~min}, 1 / 150^{\prime} 000 \times \mathrm{g}, 4^{\circ} \mathrm{C}$ ) to yield the sarkosyl insoluble Tau (SInT) as the pellet. The pellet was resuspended in TBS and stored at $-80^{\circ} \mathrm{C}$ until analysis.

\section{Biochemical analysis of brain fractions by western blotting}

For western blotting, total homogenate was diluted $1: 5$ in TBS and mixed with an equal volume of $2 \times$ SDS-PAGE sample buffer: $125 \mathrm{mM}$ Tris. $\mathrm{HCl}$ (pH6.8), 4\% (w/v) sodium dodecyl sulfate (SDS), $20 \%$ glycerol, $0.01 \%$ bromophenol blue, $5 \%(\mathrm{v} / \mathrm{v})$ beta-mercaptoethanol. Samples were heated at $95^{\circ} \mathrm{C}$ for $10 \mathrm{~min}$, and centrifuged briefly to cool and collect condensed water $(14000 \mathrm{rpm}, 10 \mathrm{~s})$. Proteins were separated in 10\% Tris-glycine SDS-PAGE gels (Anamed, Gross-Bieberau, Germany) in electrophoresis buffer $(25 \mathrm{mM}$ Tris (pH8.6), $192 \mathrm{mM}$ glycine, $0.1 \%$ SDS) and transferred to nitrocellulose 
membrane (Hybond-ECL; GE Healthcare, Belgium) in transfer buffer ( $25 \mathrm{mM}$ Tris-HCl, pH 8.6, $190 \mathrm{mM}$ Glycine, 20\% methanol). Proper protein loading and separation was routinely monitored by staining the membranes with $0.1 \%$ Ponceau red in 5\% acetic acid. Non-specific binding to membranes was blocked by incubation in 5\% non-fat dry milk in TBST $(0.1 \%$ Tween-20, $50 \mathrm{mM}$ Tris.HCl, $\mathrm{pH}$ 7.6, $150 \mathrm{mM} \mathrm{NaCl}$ ) prior to overnight incubation at $4^{\circ} \mathrm{C}$ with the $\mathrm{Mab}$ diluted in the blocking buffer. After washing in TBST, blots were incubated for $1 \mathrm{~h}$ at RT with HRPconjugated secondary goat anti-mouse antibody (DAKO, Denmark) diluted 1/10'000 in blocking buffer. After washing with TBST, blots were incubated for detection by chemiluminescence and quantitative analysis by dedicated reagents, instruments and software (ImageQuant LAS 4000 ECL system; GE Healthcare Life Sciences, Diegem, Belgium).

\section{Biochemical analysis of brain fractions by ELISA}

Microtiter plates were coated with the following capture antibodies $(2 \mu \mathrm{g} / \mathrm{ml})$ in coating buffer overnight at $4^{\circ} \mathrm{C}$ : TN5-20 [39], MC1, AD2 (BioRad, Cressier, Switzerland), or ACI-5400. Plates were washed 3 times with PBS, $0.05 \%$ Tween-20 and non-specific binding was blocked with $1 \%$ BSA in PBS $/ 0.05 \%$ Tween-20 ( $1 \mathrm{~h}$ at RT). After washing, plates were incubated with $50 \mu$ l of different brain extracts or fractions, in duplicate or triplicate, all at different dilutions in blocking buffer. After incubation for $3 \mathrm{~h}$ at RT and 3 washes, plates were incubated with a biotinylated anti-Tau TN520 detection antibody at $1 \mu \mathrm{g} / \mathrm{ml}$ for $1 \mathrm{~h}$ at RT. The TN5-20 is a panTau antibody that was generated against the N-terminus of human Tau [39]. Signals were generated by incubating with streptavidin-HRP and ortho-phenylenediamine, and the reaction was stopped with $50 \mu \mathrm{l}$ of $2 \mathrm{M} \mathrm{H}_{2} \mathrm{SO}_{4}$. A plate reader (Multiskan; Thermo Fisher, Brussels, Belgium) was used to measure the O.D. at $492 \mathrm{~nm}$. Brain extracts and fractions from TKO mice were used as the most appropriate negative control.

\section{Statistical analysis}

Data are presented as mean \pm S.D. and compared using either an unpaired $t$-test or a two-way ANOVA with a Bonferroni's post-hoc test. Pearson correlations were done to compare Tau HOMO-ELISA to MC1 or ACI-5400 ELISA results utilizing combined data from all groups. GraphPad Prism (version 5,
GraphPad Software, San Diego CA, USA) was used for all data analyses.

\section{RESULTS}

\section{ACI-5400 specifically and avidly recognized pS396-Tau in ELISA and by SPR}

ACI-5400, a murine IgG2bk purified from a hybridoma culture, reacted in ELISA assays with the linear peptide vaccine sequence when immobilized at high density, with a half maximal effective concentration $\left(\mathrm{EC}_{50}\right)$ of $0.1 \mathrm{nM}$. No reactivity was observed with the non-phosphorylated linear peptide, even at high antibody concentrations (Fig. 1A). The ACI-5400 Mab reacted also avidly with full-length recombinant human pTau protein expressed in yeast with $\mathrm{EC}_{50}=0.26 \mathrm{nM}$, but not with non-phosphorylated Tau protein (Fig. 1B). The production and characterization of human pTau protein in yeast has previously been described in detail [31]. Epitope mapping using overlapping synthetic phosphorylated peptides, further established the specificity of the Mab for Tau phosphorylated at S396. This was corroborated by the ACI-5400 absence of cross-reactivity to high concentrations of phosphorylated and non-phosphorylated synthetic peptides, with sequences derived from four known Tau phospho-epitopes: Tau5-18 (pY18), Tau196211 (pS202/pT212), Tau206-221 (pT12/pS214), and Tau401-418 (pS404/pS409; Fig. 1C).

The affinity of Mab ACI-5400 to the phosphorylated Tau peptide Tau393-408[pS396/pS404], was also monitored in real-time using SPR. Analysis of the sensorgrams and the fitted curves defined a dissociation constant $\left(\mathrm{K}_{\mathrm{D}}\right)$ of $38 \mathrm{nM}$ (Fig. 1D). Epitope mapping ELISA assays were performed with biotinylated peptides immobilized via a spacer to streptavidin coated microtiter plates. These assays confirmed previous findings that no binding was observed to any of the non-phosphorylated peptides spanning the 393-408 region, nor to peptides that only had S404 phosphorylated. Phosphorylation at S396 was both required and sufficient for binding and the additional presence of phosphorylated S404 did neither hinder nor improve the reactivity to the pS396 epitope (Supplementary Figure 1).

We concluded from the combined ELISA and SPR data that ACI-5400 reacted specifically and with high affinity to an epitope containing pS396 both on synthetic peptides and on phosphorylated recombinant protein Tau. 
A

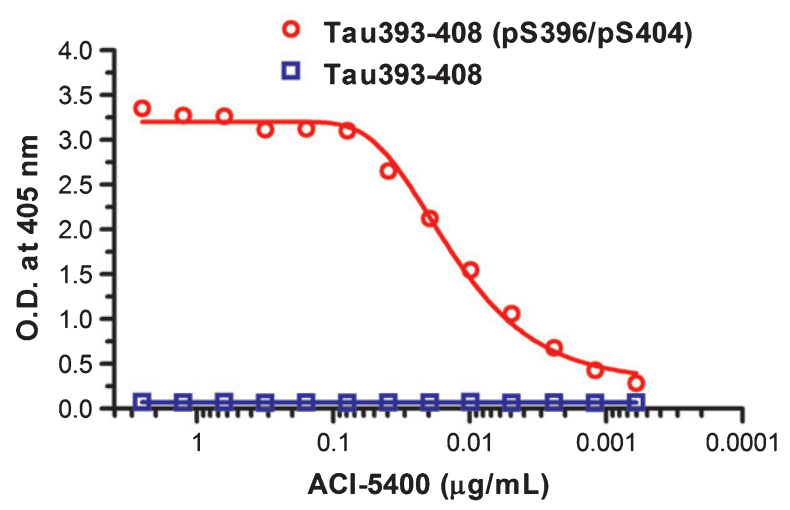

B

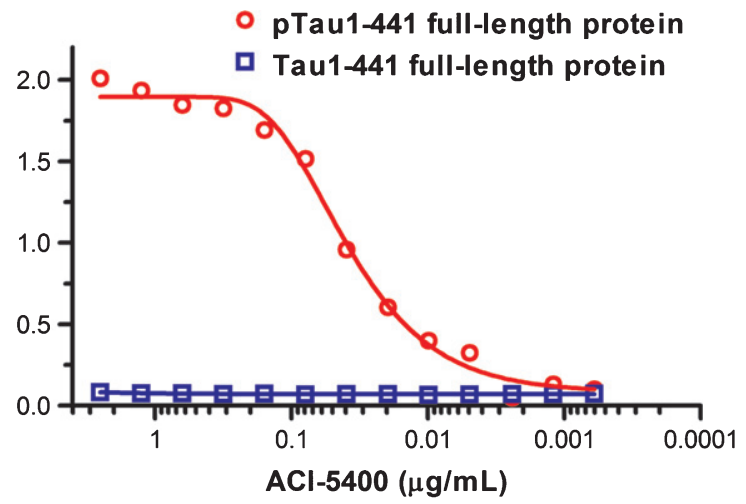

C
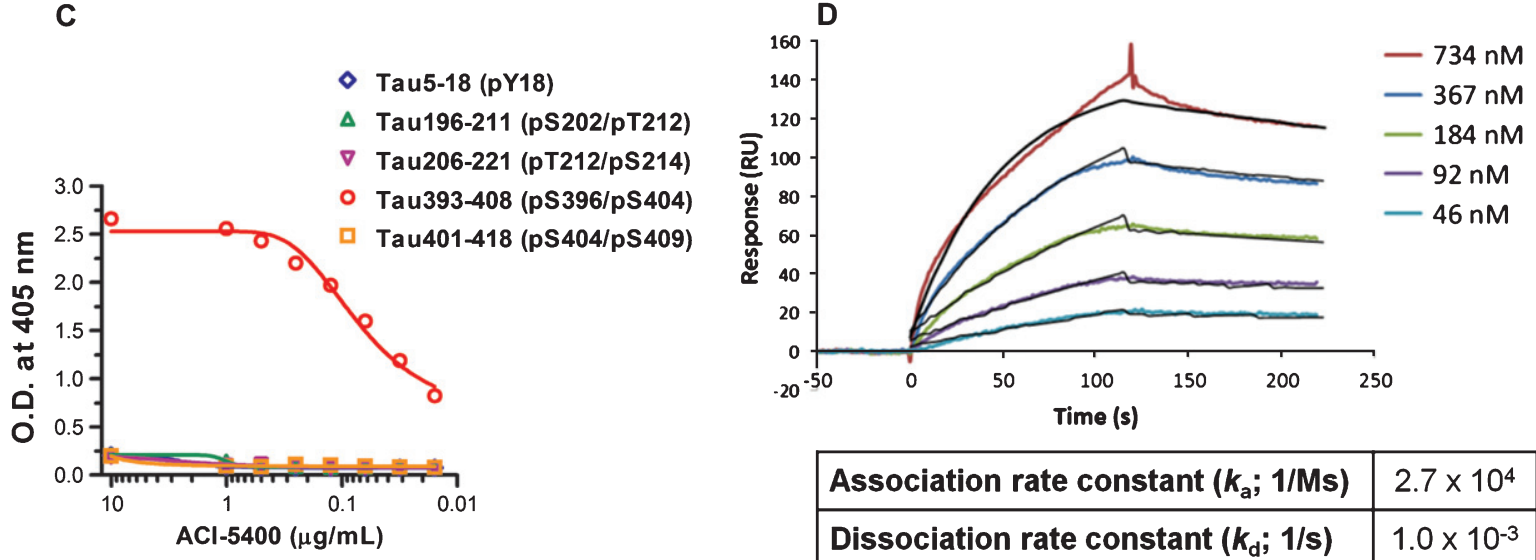

\begin{tabular}{|l|c|}
\hline Association rate constant $\left(\boldsymbol{k}_{\mathrm{a}} ; \mathbf{1 / M s}\right)$ & $2.7 \times 10^{4}$ \\
\hline Dissociation rate constant $\left(\boldsymbol{k}_{\mathrm{d}} ; \mathbf{1 / s}\right)$ & $1.0 \times 10^{-3}$ \\
\hline Dissociation constant $\left(\mathrm{K}_{\mathrm{D}} ; \mathrm{nM}\right)$ & 38 \\
\hline
\end{tabular}

Fig. 1. ACI-5400 reacts selectively with phosphorylated Tau protein and peptide in ELISA and Surface Plasmon Resonance. ELISA with increasing concentrations of ACI-5400 revealed the selectivity of the antibody for the phosphorylated form of the synthetic Tau393-408 (pS396/pS404) peptide (A) and for full-length pTau1-441 protein (B). No binding was observed to the corresponding non-phosphorylated peptide or protein Tau, or peptides corresponding to different Tau phospho sites (C). No binding was detected to the corresponding nonphosphorylated Tau peptides (not shown). Binding of antibody ACI-5400 at different concentrations as indicated, to the immobilized Tau393-408 (pS396/pS404) peptide (D). The colored curves are the SPR sensorgrams, whereas the black curves are fitted using a 1:1 Langmuir binding model.

\section{ACI-5400 recognized higher molecular-weight human pTau associated with a severe pathological phenotype}

The reaction of ACI-5400 was moreover assessed biochemically by western blotting SDS-PAGE separated total brain homogenates from two transgenic mouse strains expressing human Tau with the P301L mutation, denoted TPLH and biGT. As controls, we similarly analyzed brain extracts from wild-type FVB, and from TKO mice totally lacking mouse and human Tau [33]. In western blotting, ACI-5400 reacted with both mouse and human protein Tau, which was expected because of the sequence identity of this epitope in the human and mouse protein, VYK-S 396 -PVVSGDT-S 404 -PRH (Fig. 2). Nevertheless, the signal on murine Tau protein of apparent molecular weight (MW) of 55-60 kDa was weaker than on human Tau P301L of apparent MW of $64-68 \mathrm{kDa}$. Moreover, the antibody also reacted to the slower migrating SDS-PAGE resistant human Tau-pS396 conformers.

\section{Specific staining of tauopathy in transgenic mice}

Mab ACI-5400 recognized the well-known and accepted markers of tauopathy, as demonstrated by TAUPIR on free floating sections from old biGT 


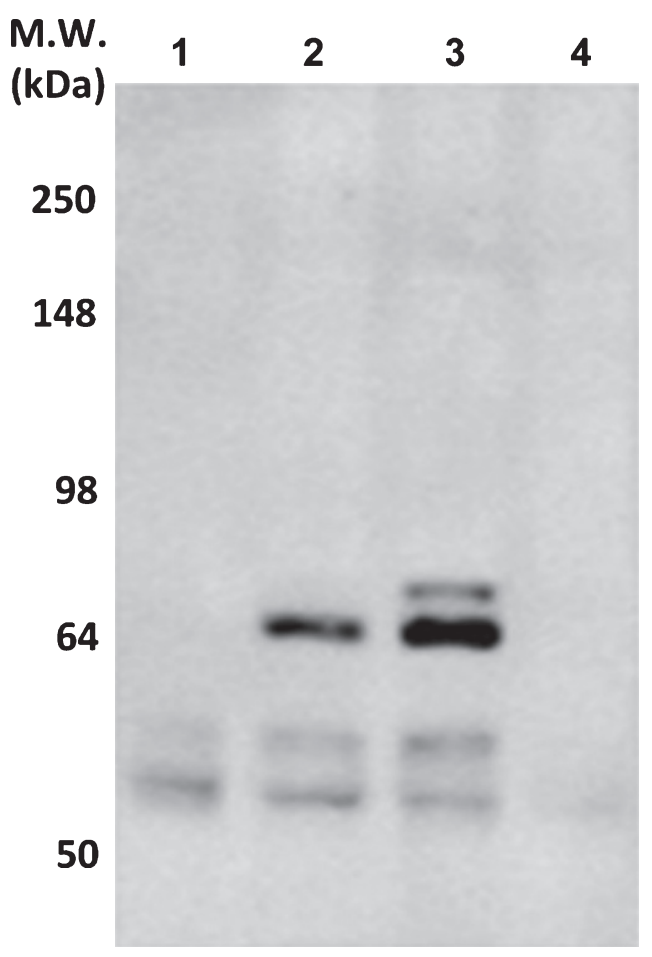

Fig. 2. ACI-5400 reacts with higher molecular-weight pTau present in a more severe tauopathy model. Western blotting with antibody ACI-5400 the un-fractionated brain extracts from mice $(\mathrm{N}=1)$ of the following genotypes: wild-type (FVB; lane 1), TPLH (lane 2), biGT (lane 3), and TKO (lane 4). A more intense reaction was observed with human pTau (64-68 kDa) compared to mouse Tau $(55-60 \mathrm{kDa})$. Note the lack of reaction with brain extracts from mice that were deficient in mouse protein Tau (lane 4), with very weak reaction caused by the secondary antibody that recognized immunoglobulins present in all brain extracts. For blotting, the ACI-5400 Mab was used at 1/3'000 dilution. M.W., molecular weight.

mice that have been characterized to develop extensive tauopathy in their forebrain [37]. Specifically, ACI-5400 decorated the tangled neurons in the cortex and CA1 of the hippocampus, with particularly noticeable reaction to fibrils and tangles in the somata and the apical dendrites of the pyramidal neurons (Fig. 3, upper panels). In addition, the reaction seen in neuronal processes demonstrated the recognition of neuropil threads, a predominant form in which helical filaments and fibrils of the Tau protein accumulate in $\mathrm{AD}$ and other tauopathies [40].

Importantly, the staining patterns visualized with ACI-5400 proved to be comparable to those produced with the AT100 Mab, widely accepted as a marker for tauopathy by immunohistochemistry (Fig. 3, lower panels). This outcome was further elaborated and confirmed by the co-localization of signals from
ACI-5400 and AT100 in brain sections from old biGT mice, as visualized by confocal microscopy (Fig. 4A). Additionally, MC1 staining co-localized nearly completely with ACI-5400 staining (Fig. 4B), further demonstrating the preference of ACI-5400 for pathological conformers of protein Tau.

Interestingly, the TAUPIR patterns obtained with ACI-5400 were notably different from those observed with a commercial polyclonal pS396 antibody. Whereas ACI-5400 stained tangles and neuropil threads, the polyclonal pS396 antibody reacted also with soma and processes of neurons that lacked tauopathy (Fig. 4C, left panel, red). These were neither marked by ACI-5400 (Fig. 4C, center panel, green) nor by AT100 (not shown), and the many sites with either red (pS396) or green (ACI-5400) signal demonstrated the lack of co-localization. Thereby, ACI-5400 demonstrated high specificity for the immuno-histopathological markers of tauopathy in the pre-clinical biGT model.

\section{ACI-5400 preferentially reacts with multimeric pTau conformers}

Analysis was extended by implementing different combinations of non-denaturing sandwich ELISAs on soluble and insoluble lysate fractions from the forebrain and brainstem of various mouse models for tauopathy: terminal TPLH, old biGT mice, and old TT4.TKO mice. Of note, in TPLH and biGT mice the mutant human Tau P301L transgene caused typical tauopathy of neurofibrillary tangles and neuropil threads in the forebrain and brainstem [37, 38]. Conversely, the human wild-type Tau4R protein in the TT4.TKO mice resulted in axonopathy with increased phosphorylation of Tau4R, but without the conformational Tau changes that lead to the formation of neurofibrillary tangles observed to some degree in TPLH mice but to a much greater extent in biGT mice [38]. We established different types of ELISA, all using the biotinylated TN5-20 Mab for detection, in combination with four different capture antibodies: (i) the TN5-20 Mab, resulting in a homotypic-ELISA (HOMO-ELISA) that by definition exclusively detects dimers or higher order multimers of protein Tau thus detecting the presence of repeated TN5-20 epitopes independent of phosphorylation status [39], (ii) the MC1 Mab to measure pathological Tau conformational alteration [41], (iii) the AD2 Mab recognizing Tau phosphorylated at S396, with a lesser requirement for phosphorylation at S404 [42, 43], and (iv) the ACI-5400 as the novel 


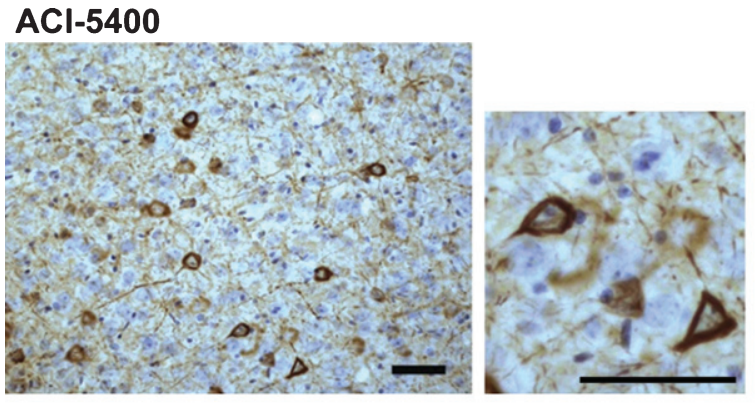

biGT, cortex

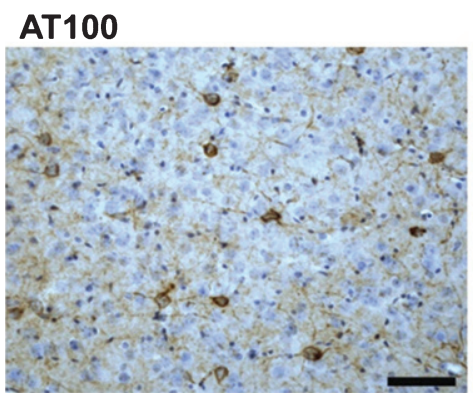

biGT, cortex

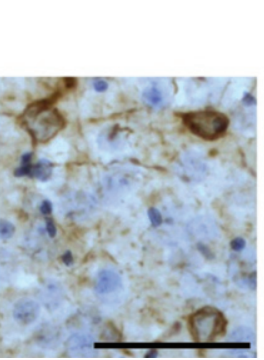

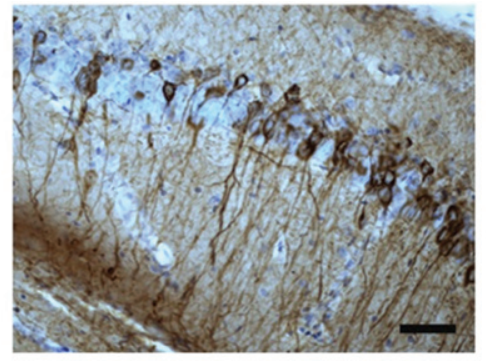

biGT, CA1

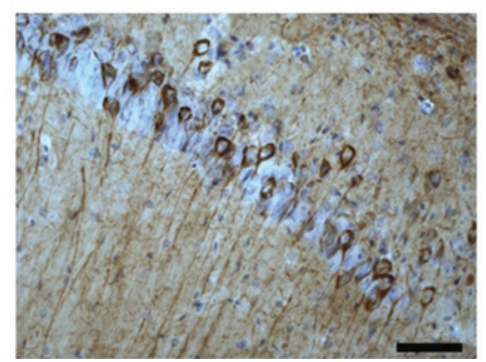

biGT, CA1

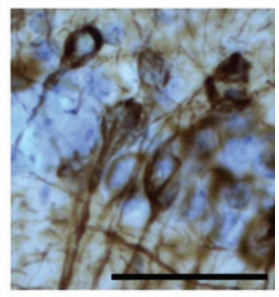

Fig. 3. ACI-5400 defines Tau pathology by reaction with tangles and neuropil threads. ACI-5400 specifically revealed neurofibrillary tangles and neuropil threads in the cortex and CA1 hippocampus of biGT mice (upper panels), with AT100 as positive control (lower panels). Enlarged images demonstrated the exquisite nature of the fibrillar tauopathy in the somata of pyramidal neurons in cortex and CA1 of old biGT mice. The following antibody dilutions were used: ACI-5400 at 1/30'000 and AT100 at 1/1'000. Scale bars $=50 \mu \mathrm{m}$.

Mab. The HOMO-ELISA (Fig. 5A) and the MC1 ELISA (Fig. 5B) demonstrated high reactivity in both the soluble (S1) and the insoluble (SInT) fractions from forebrain in biGT mice compared to TT4.TKO mice $(p<0.0001)$. From TPLH mice only the SInT fractions from both forebrain and brainstem showed low to medium reactivity for these two markers compared to TT4.TKO mice $(p<0.01)$, but significantly less than biGT mice $(p<0.0001)$. Thus, both types of ELISA yielded evidence, as expected [37], for the recognition of oligomers and/or small multimers of Tau in these samples without any reactivity in TT4.TKO mice, expressing normal human Tau. In contrast, the AD2 ELISA detected pTau in the same fractions and at comparable levels, but notably also equally well in soluble $\mathrm{S} 1$ fractions from TT4.TKO mice (Fig. 5C). Finally, ELISA with the ACI-5400 Mab (Fig. 5D) correlated very closely with the TN520 HOMO-ELISA (Fig. 5E) and the MC1 ELISA (Fig. 5F), and in contrast to the results with the AD2 Mab, did not detect pTau in S1 fractions from TT4.TKO mice $(p<0.0001)$.

The combined data corroborated the previous findings that ACI-5400 Mab binds to Tau protein, not only because of the phosphorylation at S396, but also because of a conformation that is characteristic for pathological tauopathy similar to what was originally defined by the Alz50 and MC1 Mabs [41].

\section{ACI-5400 detects inclusions signifying human tauopathy}

The immune-histopathological data obtained in the transgenic mouse models were extended to the analysis of human brains by staining and comparing sections from elderly subjects without tauopathy to patients suffering from $\mathrm{AD}$ and various tauopathies.

Staining with ACI-5400 revealed the typical Tau inclusions in brain sections from different patients diagnosed with tauopathy (Fig. 6). The results with Mab ACI-5400 were confirmed by parallel analyses using antibodies AT100 and AT8 that are generally accepted as markers for tauopathy when detected post-mortem in human brain sections. Mab ACI-5400 distinctly visualized all the pathological features in brain sections from different tauopathy cases, including neurofibrillary tangles, neuropil threads, dystrophic neurites, argyrophilic grains, ballooned 
A

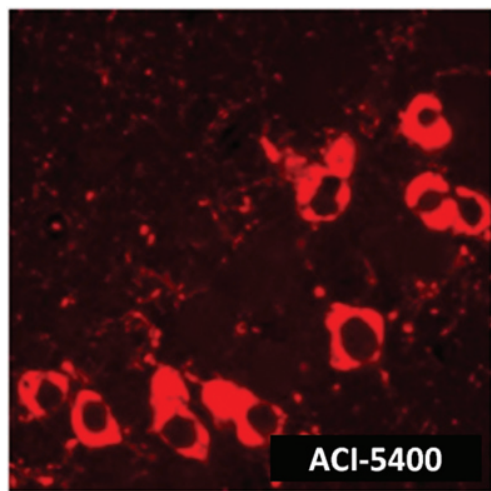

B

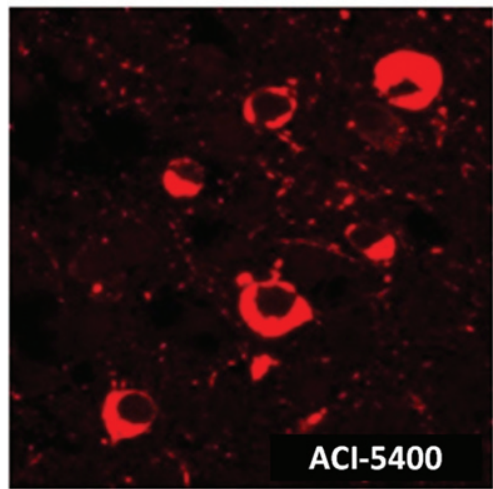

C

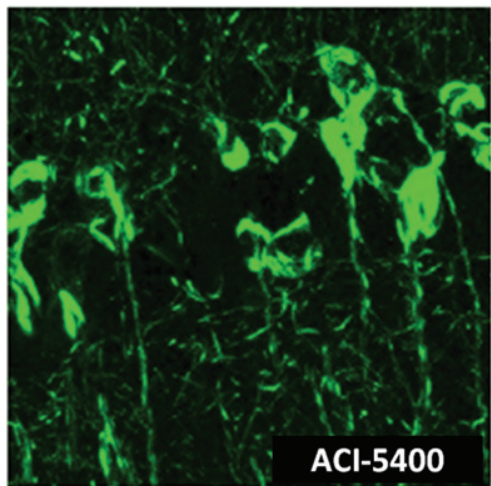

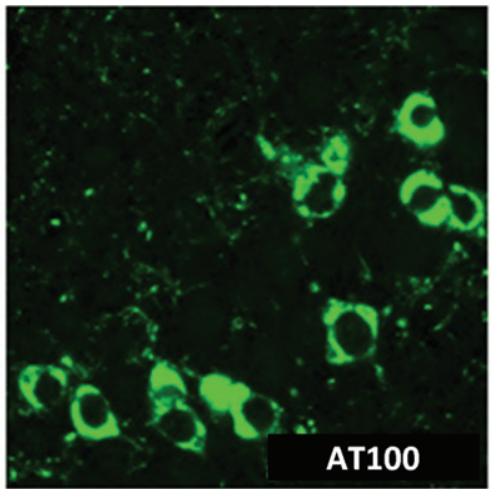
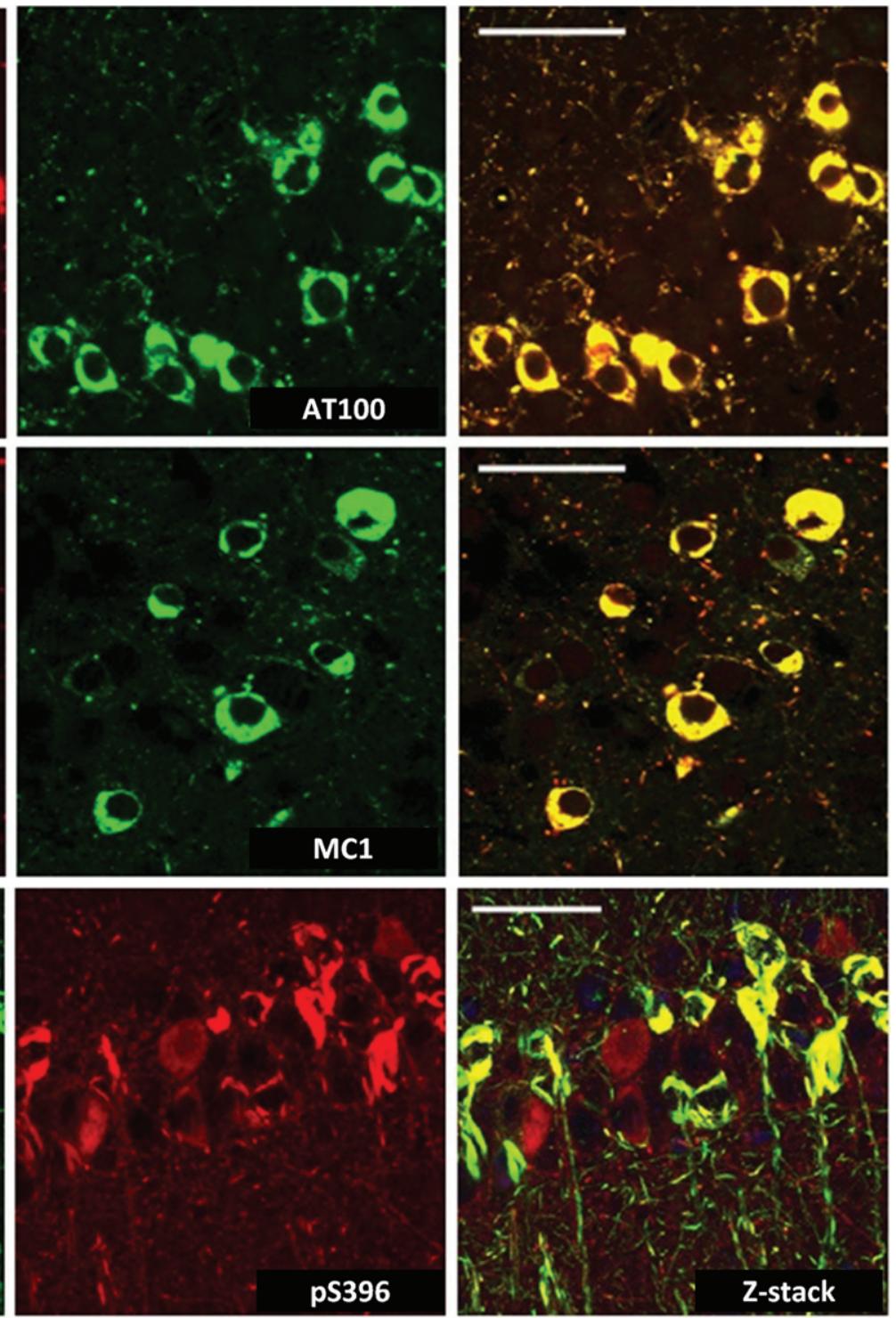

Fig. 4. ACI-5400 specifically defines Tau pathology. Reaction of ACI-5400 (red) completely coincided with that of AT100 (green, A) and $\mathrm{MC1}$ (green, B) in the somata and apical dendrites of pyramidal neurons in CA1 and in cortex of tangle-loaded old biGT mice. The commercial polyclonal antibody pS396 (red, C) additionally labeled non-tangled neurons that are neither marked by ACI-5400 (green, C) nor by AT100 (not shown). Note many sites with either red or green signal, demonstrating the lack of co-localization. To demonstrate that co-localization was absent in a number of cells, a z-stack image was produced by compiling images from different depths (Z-panes) of the section. This provided a better assessment of the apical dendrites in the CA1 region. Thereby, ACI-5400 demonstrated high specificity for the accepted immunohistopathological markers of tauopathy in the pre-clinical biGT model. The following antibody dilutions were used: ACI-5400 at 1/30'000, AT100 at 1/100, MC1 at 1/500, and antibody pS396 at 1/300. Scale bars $=40 \mu \mathrm{m}$.

neurons, coiled bodies, and other pathological features (Fig. 6). Finally, by western-blotting brain homogenates from AD patients and non-demented donors, ACI-5400 detected Tau protein specifically as the $64-68 \mathrm{kDa}$ isoforms in $\mathrm{AD}$ extracts only and not in extracts from non-demented donors (Fig. 7A). This was corroborated by a non-denaturing homotypic-
ELISA using the ACI-5400 Mab on the same homogenates from $\mathrm{AD}$ and non-AD brains (Fig. 7B).

The combination of data lends support to the conclusion that the ACI-5400 Mab was a specific biochemical and immunohistochemical marker for tauopathy detecting pathological Tau conformers phosphorylated at S396. 

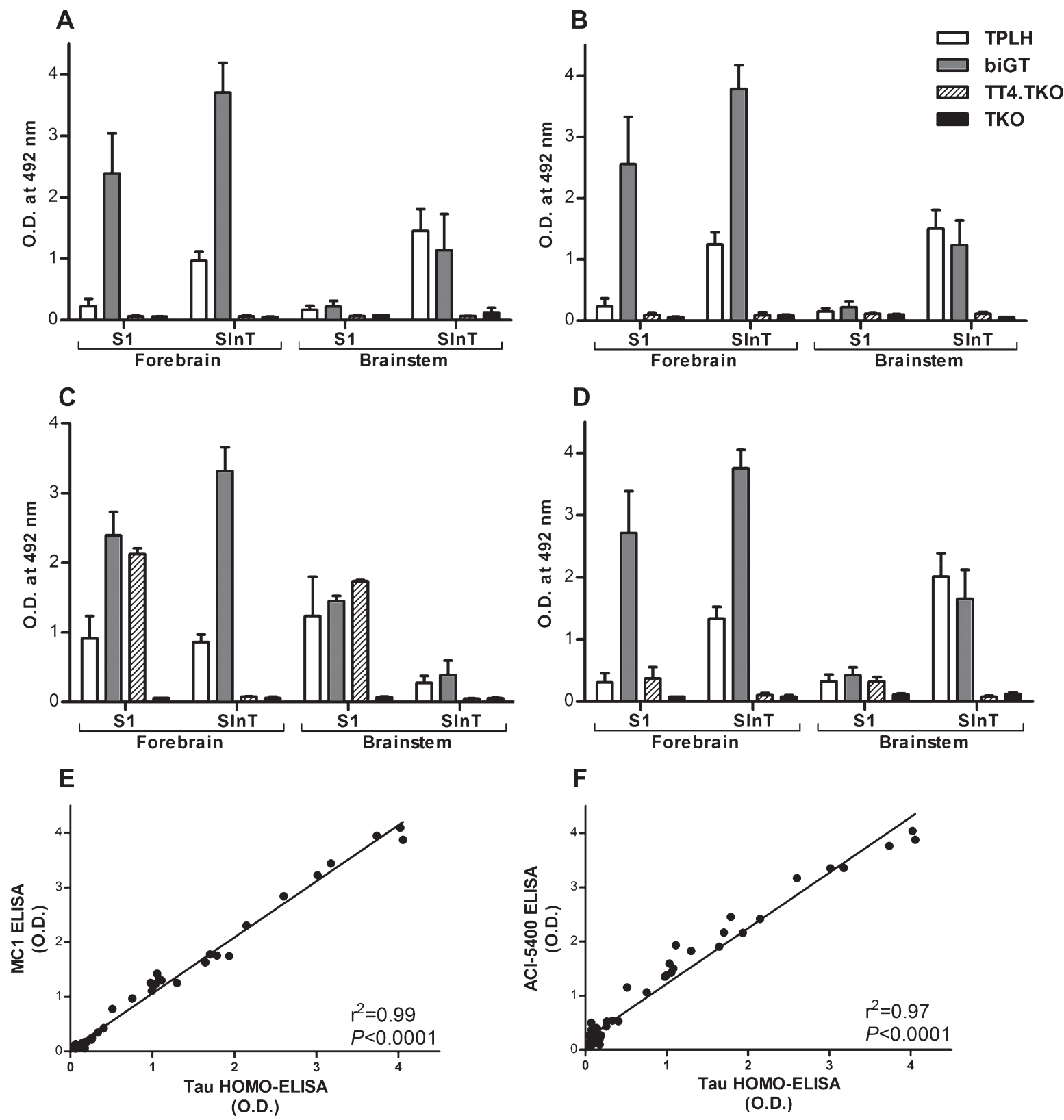

Fig. 5. An ELISA with the ACI-5400 Mab defines pTau conformers in different preclinical mouse models. Sandwich ELISAs were done using four different capture Mabs selective for Tau dimers or multimers (HOMO-ELISA, A), pathological Tau conformers (MC1 ELISA, B), Tau phosphorylated at S396/S404 (AD2 ELISA, C), or an ELISA using ACI-5400 (D). The samples were S1 or SInT brain fractions from four different preclinical tauopathy mouse models: aged TPLH $(n=4)$, aged biGT $(n=4)$, TT4.TKO $(n=2)$, and TKO $(n=2)$ mice, with data shown as means \pm S.D. Note the differences in multimeric Tau species in brainstem versus forebrain. The ACI-5400 Mab detects species in fractions that have positive signals in the HOMO-ELISA and the MC1 ELISA. The relatively high signals observed in the S1 fraction of the biGT forebrain for these three ELISA combinations are explained by the presence of small soluble Tau oligomers. The AD2 ELISA on the other hand reacts with the soluble monomeric pTau (see text for experimental details and discussion). Close correlations between the HOMO-ELISA and the MC1 ELISA (E) or the ACI-5400 ELISA (F) using all data from all mice and all fractions.

\section{DISCUSSION}

Antibodies that define structural characteristics of protein Tau have been essential tools for fundamental research to unravel structure-function relations of protein Tau and, perhaps even more so, to define specific stages of Tau pathology, either postmortem or as biomarkers. Conversely, their potential as 


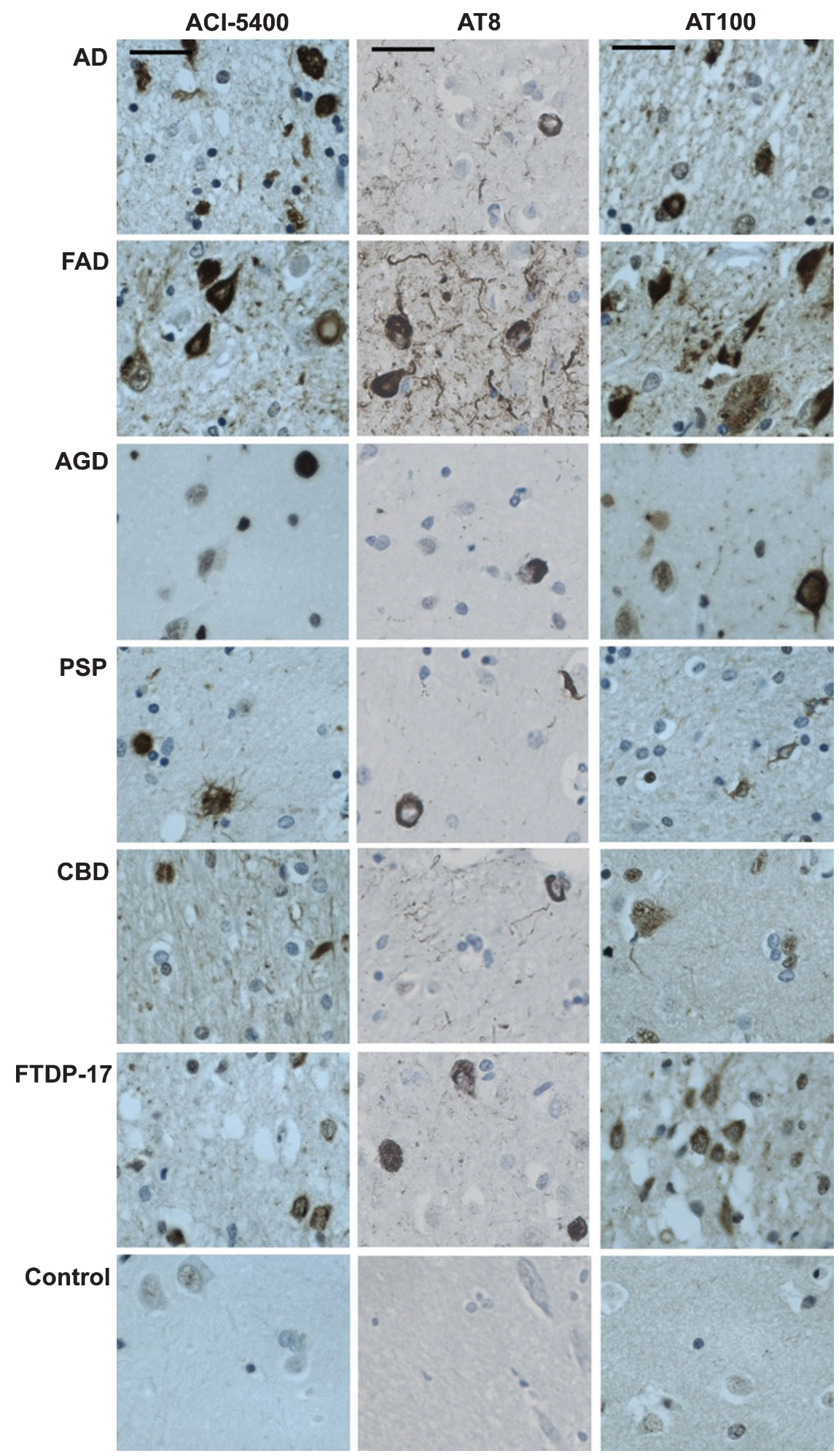

Fig. 6. ACI-5400 specifically detects Tau pathology in clinically different tauopathies. IHC with ACI-5400 revealed aggregated Tau inclusions specific for the different tauopathies (left column), denoted by standard abbreviations in the captions on the left $(n=1)$. Parallel analysis with Mabs AT8 (central column) and AT100 (right column) were done as positive controls. The following antibody dilutions were used: ACI-5400 at 1/3'000, AT8 at 1/3'000, and AT100 at 1/100. Scale bars $=40 \mu \mathrm{m}$. 
A
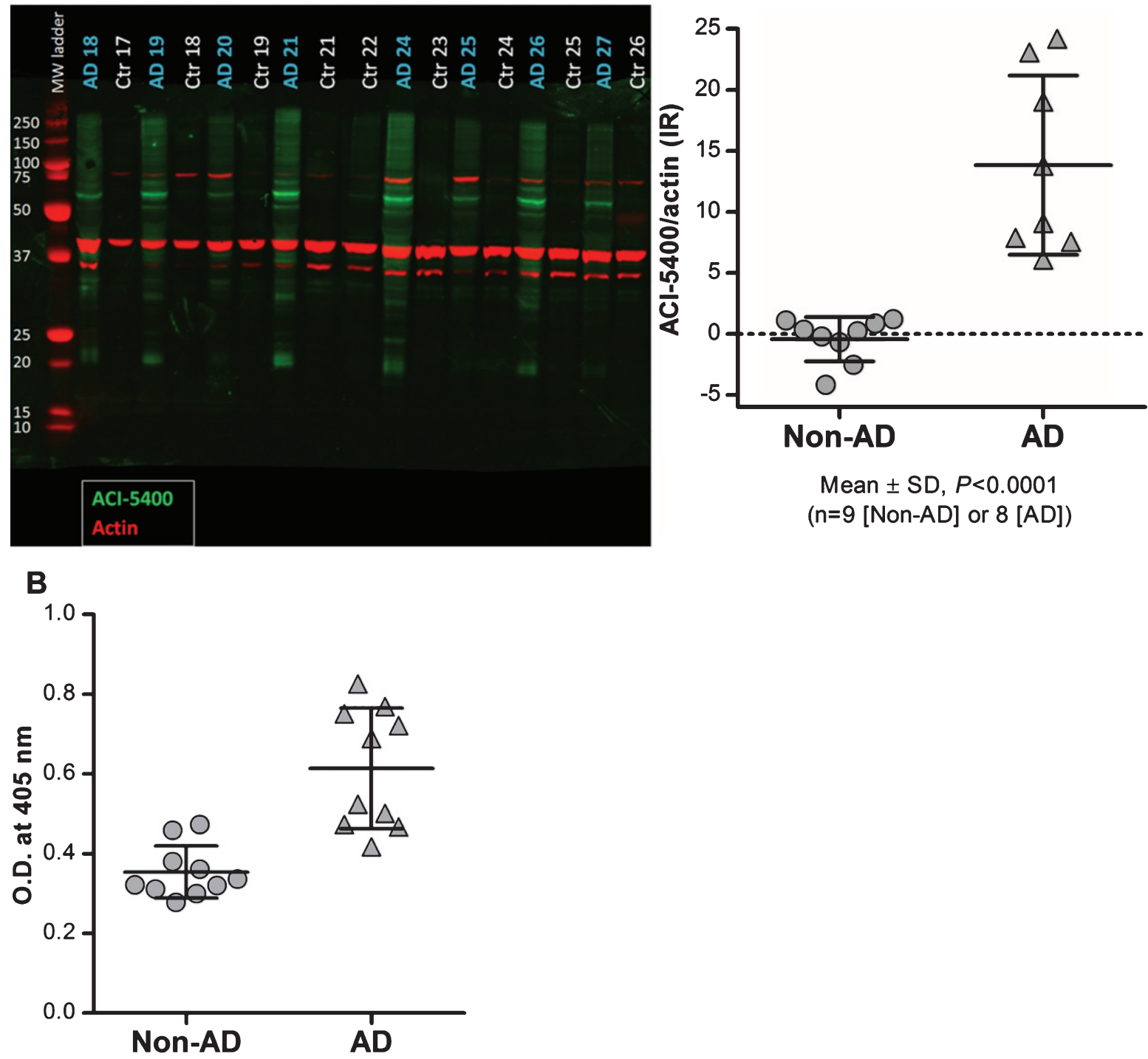

Mean $\pm S D, P<0.001,(n=10)$

Fig. 7. ACI-5400 detects significant higher levels of pathological Tau species in AD brain. Brain extracts from $\mathrm{AD}(n=8)$ and non-AD $(n=9)$ subjects were analyzed by western blotting (A) and by a homotypic-ELISA $(n=10)$ using the ACI-5400 Mab (B). Blotting with the ACI-5400 Mab for pathological Tau species is represented in panel A by green signals for ACI-5400, red signals for actin, and with quantitation shown to the left. In panel $\mathrm{A}$ and panel $\mathrm{B}$, individual values and means \pm SD are shown. In both assays the difference between non-AD and $\mathrm{AD}$ was statistically significant as indicated under each graph.

therapeutic agents to eventually cure or prevent tauopathy needs to be established. Previously we generated and validated a liposomal Tau vaccine for active immunotherapy against Tau pathology [10]. Liposomal vaccines allow for comparison of structural features on the liposome surface that are not attainable with linear peptides in solution. The vaccine carried synthetic peptides with phosphory- lated amino acids mimicking a protein sequence that comprises well-known pathological epitopes of human protein Tau, e.g., Tau393-408[pS396/pS404]. We demonstrated that the peptides attached by dipalmitoylated lysine anchors at both ends displayed $\beta$-sheet secondary structures on the liposome surface and induced an antibody response that recognized tauopathy features in brain [10]. In parallel, we gen- 
erated monoclonal antibodies from mice that showed high-titered and specific serological responses. Here we present the characterization of one monoclonal antibody, ACI-5400 that proved specific for Tau phosphorylated at S396 but moreover, had high affinity for pTau present in a conformation closely associated with Tau pathology. The composition of the peptides and the vaccine formulation were proposed to account for the generation of high-titered specific polyclonal immune responses in both wild-type and transgenic mice [10]. We analyzed scrupulously a large panel of Mabs and selected those with best affinities and selectivity for tauopathy epitopes that we propose to be of importance for fundamental as well as translational research.

The selected Mab ACI-5400 that we present here, was demonstrated to react specifically with protein Tau phosphorylated at S396, an epitope that is generated mainly by the GSK3 kinases, and known to be associated with AD-related brain pathology [37, $44,45]$. The data demonstrated that the high-affinity binding of Mab ACI-5400 to Tau protein depends on the phosphorylation of S396, but in addition detects and favors a conformation that is characteristic for tauopathy. The different non-denaturing ELISA-data demonstrated that this conformation is related, but not identical, to that defined by the established Mab MC1 [41].

The combined elements allow us to conclude that the ACI-5400 Mab defines pathologically phosphorylated conformers of protein Tau, present not only in $\mathrm{AD}$ patients and other human tauopathies, but also in aged preclinical mouse models for tauopathy. We believe that this combination of characteristics promotes the ACI-5400 Mab as a valuable tool for fundamental research, and awaits characterization as a diagnostic tool and eventually for passive immunotherapy of tauopathies, including $\mathrm{AD}$.

\section{ACKNOWLEDGMENTS}

Human brain sections were generously provided by Sigrun Roeber and Hans A. Kretzschmar, Center for Neuropathology and Prion Research (ZNP), Ludwig-Maximilians-University, Munich, Germany. We thank Peter Davies (The Feinstein Institute for Medical Research, New York, USA) for generously providing antibody MC1.

Authors' disclosures available online (http://j-alz. com/manuscript-disclosures/16-0695r3).

\section{ETHICAL APPROVALS}

All procedures performed in studies involving human participants were in accordance with the ethical standards of the institutional and/or national research committee and with the 1964 Helsinki declaration and its later amendments or comparable ethical standards. Informed consent was obtained from all individual participants included in the study, or their legal representative. All applicable international, national, and/or institutional guidelines for the care and use of animals were followed. All procedures performed in studies involving animals were in accordance with the ethical standards of the institution or practice at which the studies were conducted.

\section{SUPPLEMENTARY MATERIAL}

The supplementary material is available in the electronic version of this article: http://dx.doi. org/10.3233/JAD-160695.

\section{REFERENCES}

[1] Prince M, Wimo A, Guerchet M, Ali G-C, Wu Y-T, Prina M (2016) World Alzheimer Report 2015, The Global Impact of Dementia, An Analysis of Prevalence, incidence, Cost and Trends. Alzheimer Disease International, London, UK, pp. 1-82.

[2] Froestl W, Muhs A, Pfeifer A (2014) Cognitive enhancers (Nootropics). Part 1: Drugs interacting with receptors. Update 2014. J Alzheimers Dis 41, 961-1019.

[3] Froestl W, Muhs A, Pfeifer A (2014) Cognitive enhancers (nootropics). Part 2: Drugs interacting with enzymes. Update 2014. J Alzheimers Dis 42, 1-68.

[4] Schneider LS, Mangialasche F, Andreasen N, Feldman H, Giacobini E, Jones R, Mantua V, Mecocci P, Pani L, Winblad B, Kivipelto M (2014) Clinical trials and late-stage drug development for Alzheimer's disease: An appraisal from 1984 to 2014. J Intern Med 275, 251-283.

[5] Spillantini MG, Murrell JR, Goedert M, Farlow MR, Klug A, Ghetti B (1998) Mutation in the tau gene in familial multiple system tauopathy with presenile dementia. Proc Natl Acad Sci U S A 95, 7737-7741.

[6] Hardy JA, Higgins GA (1992) Alzheimer's disease: The amyloid cascade hypothesis. Science 256, 184-185.

[7] Duyckaerts C, Delatour B, Potier MC (2009) Classification and basic pathology of Alzheimer disease. Acta Neuropathol 118, 5-36.

[8] Nelson PT, Alafuzoff I, Bigio EH, Bouras C, Braak H, Cairns NJ, Castellani RJ, Crain BJ, Davies P, Del TK, Duyckaerts C, Frosch MP, Haroutunian V, Hof PR, Hulette CM, Hyman BT, Iwatsubo T, Jellinger KA, Jicha GA, Kovari E, Kukull WA, Leverenz JB, Love S, Mackenzie IR, Mann DM, Masliah E, McKee AC, Montine TJ, Morris JC, Schneider JA, Sonnen JA, Thal DR, Trojanowski JQ, Troncoso JC, Wisniewski T, Woltjer RL, Beach TG (2012) Correlation of Alzheimer disease neuropathologic changes with cognitive 
status: A review of the literature. J Neuropathol Exp Neurol 71, 362-381.

[9] Murray ME, Lowe VJ, Graff-Radford NR, Liesinger AM, Cannon A, Przybelski SA, Rawal B, Parisi JE, Petersen RC, Kantarci K, Ross OA, Duara R, Knopman DS, Jack CR, Jr., Dickson DW (2015) Clinicopathologic and 11C-Pittsburgh compound B implications of Thal amyloid phase across the Alzheimer's disease spectrum. Brain 138, 1370-1381.

[10] Theunis C, Crespo-Biel N, Gafner V, Pihlgren M, LopezDeber MP, Reis P, Hickman DT, Adolfsson O, Chuard N, Ndao DM, Borghgraef P, Devijver H, Van Leuven F, Pfeifer A, Muhs A (2013) Efficacy and safety of a liposome-based vaccine against protein Tau, assessed in tau.P301L mice that model tauopathy. PLoS One 8, e72301.

[11] Kontsekova E, Zilka N, Kovacech B, Novak P, Novak M (2014) First-in-man tau vaccine targeting structural determinants essential for pathological tau-tau interaction reduces tau oligomerisation and neurofibrillary degeneration in an Alzheimer's disease model. Alzheimers Res Ther 6, 44-55.

[12] Asuni AA, Boutajangout A, Quartermain D, Sigurdsson EM (2007) Immunotherapy targeting pathological tau conformers in a tangle mouse model reduces brain pathology with associated functional improvements. $J$ Neurosci $\mathbf{2 7}$, 9115-9129.

[13] Chai X, Wu S, Murray TK, Kinley R, Cella CV, Sims H, Buckner N, Hanmer J, Davies P, O’Neill MJ, Hutton ML, Citron M (2011) Passive immunization with anti-Tau antibodies in two transgenic models: Reduction of Tau pathology and delay of disease progression. $\mathrm{J}$ Biol Chem 286, 34457-34467.

[14] Boutajangout A, Ingadottir J, Davies P, Sigurdsson EM (2011) Passive immunization targeting pathological phospho-tau protein in a mouse model reduces functional decline and clears tau aggregates from the brain. $J$ Neurochem 118, 658-667.

[15] d'Abramo C, Acker CM, Jimenez HT, Davies P (2013) Tau passive immunotherapy in mutant P301L mice: Antibody affinity versus specificity. PLoS One 8, e62402.

[16] Yanamandra K, Kfoury N, Jiang H, Mahan TE, Ma S, Maloney SE, Wozniak DF, Diamond MI, Holtzman DM (2013) Anti-tau antibodies that block tau aggregate seeding in vitro markedly decrease pathology and improve cognition in vivo. Neuron 80, 402-414.

[17] Walls KC, Ager RR, Vasilevko V, Cheng D, Medeiros R, Laferla FM (2014) p-Tau immunotherapy reduces soluble and insoluble tau in aged 3xTg-AD mice. Neurosci Lett $\mathbf{5 7 5}$, 96-100.

[18] Collin L, Bohrmann B, Gopfert U, Oroszlan-Szovik K, Ozmen L, Gruninger F (2014) Neuronal uptake of tau/pS422 antibody and reduced progression of tau pathology in a mouse model of Alzheimer's disease. Brain 137, 2834-2846.

[19] d'Abramo C, Acker CM, Jimenez H, Davies P (2015) Passive immunization in JNPL3 transgenic mice using an array of phospho-tau specific antibodies. PLoS One 10, e135774.

[20] Sankaranarayanan S, Barten DM, Vana L, Devidze N, Yang L, Cadelina G, Hoque N, DeCarr L, Keenan S, Lin A, Cao Y, Snyder B, Zhang B, Nitla M, Hirschfeld G, Barrezueta N, Polson C, Wes P, Rangan VS, Cacace A, Albright CF, Meredith J Jr, Trojanowski JQ, Lee VM, Brunden KR, Ahlijanian M (2015) Passive immunization with phospho-tau antibodies reduces tau pathology and functional deficits in two distinct mouse tauopathy models. PLoS One 10, e0125614.
[21] Dai CL, Chen X, Kazim SF, Liu F, Gong CX, GrundkeIqbal I, Iqbal K (2015) Passive immunization targeting the $\mathrm{N}$-terminal projection domain of tau decreases tau pathology and improves cognition in a transgenic mouse model of Alzheimer disease and tauopathies. J Neural Transm (Vienna) 122, 607-617.

[22] Schenk D, Barbour R, Dunn W, Gordon G, Grajeda H, Guido T, Hu K, Huang J, Johnson-Wood K, Khan K, Kholodenko D, Lee M, Liao Z, Lieberburg I, Motter R, Mutter L, Soriano F, Shopp G, Vasquez N, Vandevert C, Walker S, Wogulis M, Yednock T, Games D, Seubert P (1999) Immunization with amyloid-beta attenuates Alzheimer-disease-like pathology in the PDAPP mouse. Nature 400, 173-177.

[23] Arriagada PV, Growdon JH, Hedley-Whyte ET, Hyman BT (1992) Neurofibrillary tangles but not senile plaques parallel duration and severity of Alzheimer's disease. Neurology 42, 631-639.

[24] Vandermeeren M, Mercken M, Vanmechelen E, Six J, van d, V, Martin JJ, Cras P (1993) Detection of tau proteins in normal and Alzheimer's disease cerebrospinal fluid with a sensitive sandwich enzyme-linked immunosorbent assay. J Neurochem 61, 1828-1834.

[25] Hu YY, He SS, Wang X, Duan QH, Grundke-Iqbal I, Iqbal K, Wang J (2002) Levels of nonphosphorylated and phosphorylated tau in cerebrospinal fluid of Alzheimer's disease patients: An ultrasensitive bienzyme-substraterecycle enzyme-linked immunosorbent assay. Am J Pathol 160, 1269-1278.

[26] Hickman DT, Lopez-Deber MP, Ndao DM, Silva AB, Nand D, Pihlgren M, Giriens V, Madani R, St-Pierre A, Karastaneva H, Nagel-Steger L, Willbold D, Riesner D, Nicolau C, Baldus M, Pfeifer A, Muhs A (2011) Sequenceindependent control of peptide conformation in liposomal vaccines for targeting protein misfolding diseases. $J$ Biol Chem 286, 13966-13976.

[27] Muhs A, Hickman DT, Pihlgren M, Chuard N, Giriens V, Meerschman C, Van der Auwera I, Van Leuven F, Sugawara M, Weingertner MC, Bechinger B, Greferath R, Kolonko N, Nagel-Steger L, Riesner D, Brady RO, Pfeifer A, Nicolau C (2007) Liposomal vaccines with conformation-specific amyloid peptide antigens define immune response and efficacy in APP transgenic mice. Proc Natl Acad Sci U S A 104, 9810-9815.

[28] Nicolau C, Greferath R, Balaban TS, Lazarte JE, Hopkins RJ (2002) A liposome-based therapeutic vaccine against beta-amyloid plaques on the pancreas of transgenic NORBA mice. Proc Natl Acad Sci U S A 99, 2332-2337.

[29] Pihlgren M, Silva AB, Madani R, Giriens V, Waeckerle-Men Y, Fettelschoss A, Hickman DT, Lopez-Deber MP, Ndao DM, Vukicevic M, Buccarello AL, Gafner V, Chuard N, Reis P, Piorkowska K, Pfeifer A, Kundig TM, Muhs A, Johansen P (2013) TLR4 and TRIF-dependent stimulation of B lymphocytes by peptide liposomes enables T-cell independent isotype switch in mice. Blood 121, 85-94.

[30] Bramblett GT, Goedert M, Jakes R, Merrick SE, Trojanowski JQ, Lee VM(1993) Abnormal tau phosphorylation at Ser396 in Alzheimer's disease recapitulates development and contributes to reduced microtubule binding. Neuron 10, 1089-1099.

[31] Vandebroek T, Vanhelmont T, Terwel D, Borghgraef P, Lemaire K, Snauwaert J, Wera S, Van Leuven F, Winderickx J (2005) Identification and isolation of a hyperphosphorylated, conformationally changed intermediate of human protein tau expressed in yeast. Biochemistry 44, 11466-11475. 
[32] Karlsson R, Michaelsson A, Mattsson L (1991) Kinetic analysis of monoclonal antibody-antigen interactions with a new biosensor based analytical system. J Immunol Methods 145, 229-240.

[33] Tucker KL, Meyer M, Barde YA (2001) Neurotrophins are required for nerve growth during development. Nat Neurosci 4, 29-37.

[34] Biernat J, Mandelkow EM, Schroter C, Lichtenberg-Kraag B, Steiner B, Berling B, Meyer H, Mercken M, Vandermeeren A, Goedert M (1992) The switch of tau protein to an Alzheimer-like state includes the phosphorylation of two serine-proline motifs upstream of the microtubule binding region. EMBO J 11, 1593-1597.

[35] Mercken M, Vandermeeren M, Lubke U, Six J, Boons J, Van de Voorde A, Martin JJ, Gheuens J (1992) Monoclonal antibodies with selective specificity for Alzheimer Tau are directed against phosphatase-sensitive epitopes. Acta Neuropathol 84, 265-272.

[36] Zheng-Fischhofer Q, Biernat J, Mandelkow EM, Illenberger S, Godemann R, Mandelkow E (1998) Sequential phosphorylation of Tau by glycogen synthase kinase-3beta and protein kinase A at Thr212 and Ser214 generates the Alzheimer-specific epitope of antibody AT100 and requires a paired-helical-filament-like conformation. Eur J Biochem 252, 542-552.

[37] Terwel D, Muyllaert D, Dewachter I, Borghgraef P, Croes S, Devijver H, Van Leuven F (2008) Amyloid activates GSK3 beta to aggravate neuronal tauopathy in bigenic mice. Am J Pathol 172, 786-798.

[38] Terwel D, Lasrado R, Snauwaert J, Vandeweert E, Van Haesendonck C, Borghgraef P, Van Leuven F (2005) Changed conformation of mutant Tau-P301L underlies the moribund tauopathy, absent in progressive, nonlethal axonopathy of Tau-4R/2N transgenic mice. J Biol Chem 280, 3963-3973.
[39] Crespo-Biel N, Theunis C, Borghgraef P, Lechat B, Devijver H, Maurin H, Van Leuven F (2014) Phosphorylation of protein Tau by GSK3 $\beta$ prolongs survival of bigenic Tau.P301LxGSK3 $\beta$ mice by delaying brainstem tauopathy. Neurobiol Dis 67, 119-132.

[40] Mitchell TW, Nissanov J, Han LY, Mufson EJ, Schneider JA, Cochran EJ, Bennett DA, Lee VM, Trojanowski JQ, Arnold SE (2000) Novel method to quantify neuropil threads in brains from elders with or without cognitive impairment. J Histochem Cytochem 48, 1627-1638.

[41] Jicha GA, Bowser R, Kazam IG, Davies P (1997) Alz-50 and MC-1, a new monoclonal antibody raised to paired helical filaments, recognize conformational epitopes on recombinant tau. J Neurosci Res 48, 128-132.

[42] Reig S, Buee-Scherrer V, Mourton-Gilles C, Defossez A, Delacourte A, Beauvillain JC, Mazzuca M (1995) Immunogold labelling of paired helical filaments and amyloid fibrils by specific monoclonal and polyclonal antibodies. Acta Neuropathol 90, 441-447.

[43] Buee-Scherrer V, Condamines O, Mourton-Gilles C, Jakes R, Goedert M, Pau B, Delacourte A (1996) AD2, a phosphorylation-dependent monoclonal antibody directed against tau proteins found in Alzheimer's disease. Brain Res Mol Brain Res 39, 79-88.

[44] Jaworski T, Dewachter I, Lechat B, Gees M, Kremer A, Demedts D, Borghgraef P, Devijver H, Kugler S, Patel S, Woodgett JR, Van Leuven F (2011) GSK-3 $\alpha / \beta$ kinases and amyloid production in vivo. Nature 480, E4-E5.

[45] Kremer A, Louis JV, Jaworski T, Van Leuven F (2011) GSK3 and Alzheimer's disease: Facts and fiction... Front Mol Neurosci 4, 17. 